\title{
Influence of oral pH Environment in the Corrosion Resistance of Cr-Co-Mo alloy Used for Dentistry Prosthetic Components
}

\author{
Francielly Moura de Souza Soares $^{a}{ }^{\circledR}$, Ana Isabel de Carvalho Santana ${ }^{b}$, Luiza Braga Ferreira \\ dos Santos ${ }^{a}$, Paula Anastácia Morais Cairo Gomes ${ }^{a}$, Emília dos Santos Monteiro ${ }^{\circledR}$, Maria Elisa \\ Rodrigues Coimbra ${ }^{a *}$, Carlos Nelson Elias ${ }^{a}$
}

${ }^{a}$ Instituto Militar de Engenharia, Biomateriais, Rio de Janeiro, RJ, Brasil

${ }^{b}$ Centro Universitário Estadual da Zona Oeste, Rio de Janeiro, RJ, Brasil

Received: May 9, 2019; Revised: December 31, 2019; Accepted: February 17, 2020

\begin{abstract}
The Cr-Co-Mo alloys are commonly used in dentistry for prosthetic components and dental implant supported prosthesis. These alloys present high corrosion resistance owing to a passive oxide film on the surface. However, the oral environment is an aggressive system, due to $\mathrm{pH}$ variation, chloride and fluoride ions presence, that can decrease the metal alloy corrosion resistance. Although Cr-Co-Mo alloys have been used for a long time, their electrochemical properties on different $\mathrm{pH}$ have not been studied yet. This study aimed to evaluate the electrochemical properties of Cr-Co-Mo alloy in $\mathrm{NaCl} 0.9 \%$ solution in different $\mathrm{pH}$ and mouthwash solution. To imitate the oral environment, electrolytes with a pH equal to 2,3, and 6 were used. Corrosion studies were performed by open circuit potential observation, potentiodynamic polarization curve, chronoamperometry and electrochemical impedance. The results showed that the analyzed alloy has good corrosion resistance under experimental conditions, although the acidified $\mathrm{NaCl} 0.9 \%$ solution increased the corrosion current, particularly in cathodic potentials.
\end{abstract}

Keywords: Cobalt-Chromium-Molybdenum, Corrosion, Resistance, Biomaterials.

\section{Literature Review}

Dental implant systems are used for replace a lost tooth and support a dental prosthesis. Their function is to transfer to the maxillary bones the masticatory forces, to reestablish the correct masticatory function ${ }^{1}$ and improve the patient esthetic. The dental implant-supported prosthesis structure is composed of the implant, prosthetic components (pillar or abutment), component screw, and dental crown. The prosthetic components are fixed to the implant with one screw, and the crown is attached to the pillar using screw or cement, building the structure implant-prosthesis system ${ }^{2,3}$.

Some metal alloys are used for manufacturing the dental implant-prosthesis structure, such as stainless steel, titanium, cobalt-chromium (Co-Cr) and nickel-titanium (Ni-Ti) and cobalt-chromium-nickel (Co-Cr-Ni). One of the problems with prosthesis degradation occurs due to contact with another alloy, especially with the implant. The alloys more often used as dental implant manufacturing are commercially pure titanium (ASTM F67) and Ti-6Al-4V alloy (ASTM F136) ${ }^{4-6}$. For the prosthesis components the Co-Cr-Mo (ASTM F1537) and Ti-6Al-4V (ASTM F136) are the most used; for abutment screw Ti-6Al-4V (ASTM F136) is used. These alloys are used because of their mechanical properties, biocompatibility, and corrosion resistance ${ }^{7}$. Nevertheless, due to the contact of different alloys in the dental implant

*e-mail: maria.coimbra@gmail.com structure and the aggressive oral environment, it tends to occur corrosion in these alloys with the release of toxic ions.

Biomaterials can exhibit different types of corrosion in saliva contact. Among the various types of corrosion, the most common are pitting, galvanic, and biological ${ }^{8}$. Some factors, such as presence of chlorine and fluoride ions, can interfere the metallic corrosion resistance in oral environment. For Co-Cr-Mo alloys, the presence of bicarbonate changes the corrosion resistance; presence of bacterial plaque, $\mathrm{pH}$ and temperature variation, food and soft drinks, and micromovement can also affect the corrosion resistance of these alloys $^{9-11}$.

The Cr-Co-Mo dental prosthesis alloy corrosion releases ion into the organism, reduces the material durability, and provokes patient health problems. A large amount of $\mathrm{Cr}$ ions released to the organism could cause cancer and DNA damage. While great amount of Co ions release can cause cardiomyopathy, anorexia and polycythemia ${ }^{9}$. A lot of studies have been carrying out to verify the behavior of the passive film, chemical composition, and the electrochemical behavior of this alloy ${ }^{12}$. Electrochemical mechanisms that drive to release of metal ions from $\mathrm{Cr}$-Co-Mo prostheses are unexplained, and the oral factors that lead toward this release is not recognized yet.

The goal of this study was to evaluate the corrosion resistance of Co-Cr-Mo alloy applied in dental implant prosthetic components. Chronoamperometry (potentiostatic 
polarization) analysis and electrochemical impedance spectroscopy were carried out to analyze the influence of $\mathrm{pH}$ on oral environment.

\section{Experimental Procedures}

Cylinders made of Co-Cr-Mo alloy commonly used in dental implant prosthetic components (abutment) were analyzed. Conexão Sistema de Próteses Co (Arujá, SP, Brazil) provided all samples for the research. Co-Cr-Mo alloy was specified by the technical standard ASTM F1537 with nominal chemical composition of $\mathrm{Co}-28 \mathrm{Cr}-6 \mathrm{Mo}$.

A semi quantitative analysis of the alloy chemical composition was determined by energy dispersive spectroscopy (EDS). The EDS analysis was made using a Quanta FEG 250 scanning electron microscope.

The electrochemical corrosion testing was evaluated in two electrolytes: $\mathrm{NaCl} 0.9 \%$ and mouthwash solution commercially available. The mouthwash chemical composition is presented in Table $1 . \mathrm{HCl}$ was used for $\mathrm{pH}$ adjustment of the $\mathrm{NaCl}$ solution. After immersion in the electrolyte, the sample was measured by the open-circuit potential (OCP). Electrochemical analysis for open circuit potential (OCP) measurement and potential dynamic polarization curve were made by the Omnimetra Instruments, model PG-3901 potentiostat.

Chronoamperometry (potentiostatic polarization) analysis and electrochemical impedance spectroscopy were made by AUTOLAB potentiostat, model PGSTAT 302N.

For electrochemical testing, each cylinder sample was embedded in acrylic resin with $1 \mathrm{~cm}^{2}$ of the surface area exposed, and connected to the copper wire. Before the electrochemical testing, the surface of the working electrode was prepared by metallography using silicon carbide sandpaper (from 200 to 1.200 mesh) followed by ultrasound cleaning in ethanol and distilled water. The purpose of cylinder polishing was to obtain surfaces similar to those of commercial abutment.

A three-electrode cell setup was used: which consisted of a saturated calomel reference electrode (SCE), platinum (Pt) counter electrode, and a specimen as working electrode.

The first test to analyze the corrosion resistance of the material was OCP. This technique is the equilibrium potential presented by a metal related with its immersed environment. Time to reach equilibrium depends on the metal alloy composition, and there is no technical standard specification to establish this time. For this study, one hour was adopted.

Potentiostatic polarization is one of most principal techniques to study corrosion resistance on different alloys. The curves were obtained after OCP measurements, with a scan rate of $0.01 \mathrm{~V} / \mathrm{s}$ in the range from $-1 \mathrm{~V}$ to $1 \mathrm{~V}$.
The electrochemical cell used for chronoamperometry (potentiostatic polarization) analysis, and electrochemical impedance analyses were similar the one used at electrochemical analyses with three electrodes: calomel reference electrode, a Pt counter electrode and the sample as working electrode.

Chronoamperometry analyses were performed using different potentials that were chosen from potentiodynamic polarization curve. The chosen ones were $150 \mathrm{mV},-150 \mathrm{mV}$, $-300 \mathrm{mV}$, and $-800 \mathrm{mV}$.

Electrochemical impedance was made using the following parameters: amplitude $7 \mathrm{mV}$ in relation to open circuit potential, resolution of 7 point per decade and frequency from $3 \mathrm{mHz}$ to $100 \mathrm{mHz}$. Before to electrochemical impedance performance, the open circuit potential (OCP) was stabilized for 3,600 s. All impedance measurements were made at open circuit potential and the electrochemical experiments were performed in naturally aerated conditions.

Considering that in the oral environment there is a large $\mathrm{pH}$ variation, the corrosion tests were performed into electrolyte with $\mathrm{pH}$ equal 2, 3 and 6 . The $\mathrm{pH}$ variation in the oral environment can be associated to ingestion of some foods and soft drinks, digestive process, and bile excretion among others. Soft drinks can decrease the mouth $\mathrm{pH}$ to extremely acid values. Juice and beverage can lead to $\mathrm{pH} 2$. During digestive process, oral $\mathrm{pH}$ can reach to less than 4.5. The saliva neutralization takes from 30 to 60 minutes. During this period dental materials in the oral environment are exposed to $\mathrm{pH}$ variation that can result in lifetime reduction and ions releasing ${ }^{13,14}$.

\section{Results and Discussion}

Table 2 and Figure 1 show the EDS semi quantitative chemical composition analyze. The chemical composition was close to those informed by the manufacturer and by the technical standard specification ASTM F1537 (Standard Specification for Wrought Cobalt-28Chromium-6Molybdenum Alloys for Surgical Implants (UNS R31537, UNS R31538, and UNS R31539).

At first, it was measured the evolution of OCP during 3,600 s. Figure 2 shows the obtained OCP curves after immersion in three different $\mathrm{pH}(2,3$ and 6$) \mathrm{NaCl} 0.9 \%$ solutions and in mouthwash solution (EB). No significance difference among the corrosion potential of the alloy in different solution was observed. The acidification of $\mathrm{NaCl} 0.9 \%$ solution and mouthwash solution did not show potential corrosion $\left(\mathrm{E}_{\text {corr }}\right)$ variation of OCP results. However, a potential tendency dislocating to more noble values could be observed with $\mathrm{pH}$ increase. OCP values

Table 1. Mouthwash chemical composition (Plax, Colgate Palmolive Industrial Ltda, São Paulo, Brazil).

\begin{tabular}{cccccc}
\hline Chemical components & Cetypyridirium Chloride & Water & Glycerin & Potassium Sorbate & Sodium Fluoride \\
\hline $0.075 \%$ & - & - & - & $225 \mathrm{ppm}$ \\
\hline
\end{tabular}


Table 2. Semi quantitative EDS of the Co-Cr-Mo chemical composition analysis.

\begin{tabular}{lccc}
\hline Element & Normalized \%weight & \% atomic & Error 3 sigma (\%weight) \\
\hline Co & 68.75 & 66.35 & 1.78 \\
Cr & 27.05 & 29.60 & 0.69 \\
Mo & 3.76 & 2.23 & 0.15 \\
O & 0.22 & 0.80 & 0.08 \\
C & 0.22 & 1.02 & 0.10 \\
& 100.00 & 100.00 & \\
\hline
\end{tabular}

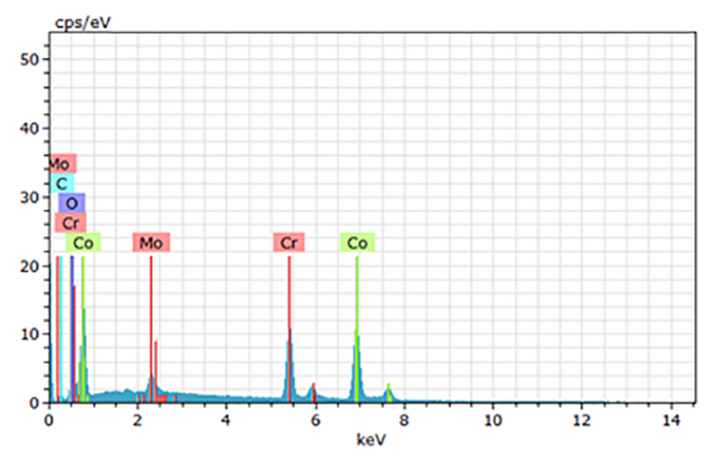

Figure 1. EDS spectra of Co-Cr-Mo for chemical composition evaluation

were approximately $-150 \mathrm{mV}$ and these results are presented in Table 3. The high corrosion resistance of the Co-Cr-Mo alloy is attributed to the formation of a passive chromium oxide film on the surface ${ }^{15,16}$. The observed behavior is similar to the one reported by Lopes et al $(2010)^{15}$, that showed that the dislocation to more noble potentials indicates the passive film formation that leads to a higher corrosion resistance.

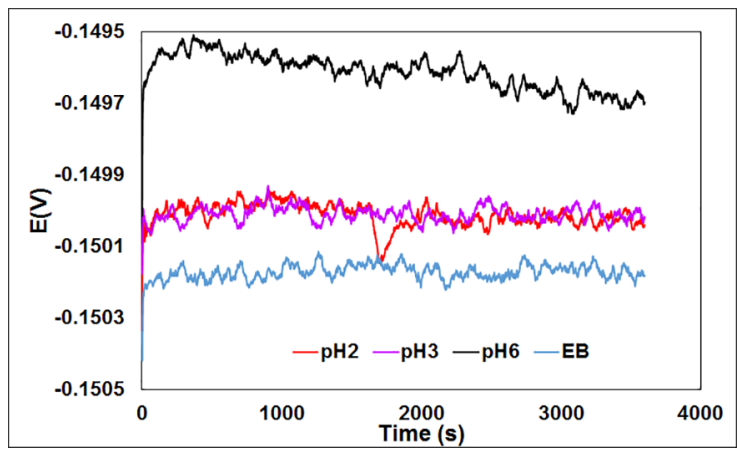

Figure 2. OCP curves of $\mathrm{Co}-\mathrm{Cr}-\mathrm{Mo}$ alloy in $\mathrm{NaCl} 0.9 \%$ solution with different $\mathrm{pH}(2,3$ and 6$)$ and in mouthwash solution (EB)
Figure 3 shows the anodic polarization curve of $\mathrm{Co}$ $\mathrm{Cr}-\mathrm{Mo}$ alloy in $\mathrm{NaCl} 0.9 \%$ solution with different $\mathrm{pH}$ and in mouthwash solution (EB). It is possible to observe that the acidification of the solution and presence of fluoride affect the corrosion resistance of the alloy. The corrosion current increases as the $\mathrm{pH}$ decreases, especially at cathodic potential. This result confirmed data of Pourbaix diagram for chemical elements that compose the alloy, which shows that acidification of the solution, can affect the corrosion resistance of the elements ${ }^{17}$.

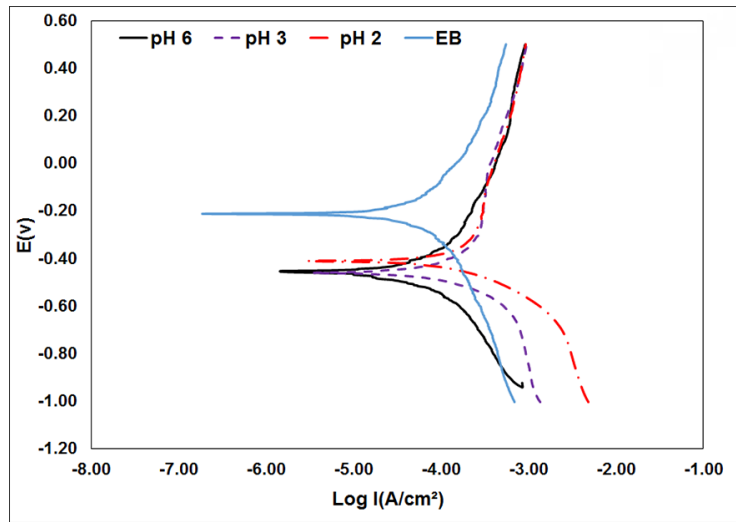

Figure 3. Anodic polarization curves of Co-Cr-Mo alloy in $\mathrm{NaCl}$ $0.9 \%$ solution with different $\mathrm{pH}$ and in mouthwash solution (EB)

In the cathodic region with potential lower than $\mathrm{E}_{\text {corr }}$ it was possible to observe a significant increase in the current density. The displacement of the current to high value can be associated with the greater evolution of hydrogen on the alloy surface. This result indicates that in more acid solution the corrosion resistance decreases and increases the release of metallic ions. It was observed that at corrosion potential close to $\mathrm{E}_{\text {corr }}$ and with more positive potential values, the corrosion current increases as $\mathrm{pH}$ decreases.

Table 3. Electrochemical parameters measured from the anodic polarization curves.

\begin{tabular}{lccc}
\hline Electrolyte & OCP & $\mathbf{E}_{\text {corr }}(\mathbf{v})$ & $\mathbf{I}_{\text {pass }}\left(\mathbf{A} / \mathbf{c m}^{2}\right)$ \\
\hline $\mathrm{NaCl} \mathrm{pH6}$ & -0.1498 & $-0.4427 \pm 0.009$ & $-3.40 \pm 0.350$ \\
$\mathrm{NaCl} \mathrm{pH3}$ & -0.1500 & $-0.3293 \pm 0.055$ & $-3.35 \pm 0.252$ \\
$\mathrm{NaCl} \mathrm{pH} 2$ & -0.1500 & $-0.4120 \pm 0.009$ & $-3.36 \pm 0.262$ \\
$\mathrm{~EB} *$ & -0.1503 & $-0.2112 \pm 0.037$ & $-3.57 \pm 0.335$ \\
\hline
\end{tabular}

*EB - Mouthwash solution 
Opposite results can be observed in the curves with the oral mouthwash tests. Adislocation of the corrosion potential to more positive potential, close to zero occurred. It is possible to affirm that the use of mouthwash with fluoride did not increase the CoCr-Mo alloy corrosion, but the alloy corrosion exposure to acid $\mathrm{pH}$ increases. The corrosion current increasing can be explained by the model proposed by Pourbaix and his proposal diagram that compares $\mathrm{pH}$ and potential ${ }^{17}$. Cr diagram shows that in $\mathrm{pH}$ below 4 and between $-1 \mathrm{~V}$ to $0.200 \mathrm{~V}$, the component is out of the stability region and can suffer corrosion. Co in more negative potential has a greater region of chemical stability. Corrosion and ion release of Mo at $\mathrm{pH}$ below 4 and over $-0.200 \mathrm{~V}$ occurs. This result shows that the corrosion resistance of dental prosthesis components made with Cr-Co-Mo alloy is influenced by the environment $\mathrm{pH}$ variation.

The higher the hydrogen concentration in the environment, the greater is the corrosion current. This result is critical for patients who drink sodas. One example is that the dental prosthesis components corrosion could be increased by soft drink. Chloride ions have higher influence in the corrosion resistance of $\mathrm{Co}-\mathrm{Cr}$ Mo alloy than fluoride ions.

Mouthwash solutions are very used for prevent bacterial plaque and helps oral hygiene. Some specialist recommends mouthwash solutions daily use every $12 \mathrm{~h}$. However, others affirm that some care must be taken with continuous use of these solutions. By lack of information, many people think that the mouthwash solutions do not cause any harm and use it after every tooth brushing every day. The use of these solutions in the wrong way can cause cancer, teeth yellowing and decrease the sensitivity of the taste. Another effect is at commercially pure titanium dental implants because the presence of fluoride can influence the corrosion resistance ${ }^{13}$.

Chloride ions have higher influence in the Co-Cr-Mo alloy corrosion than fluoride ions. However, the fluoride concentration analyzed in the present work was lower than the chloride one. Silva et al (2011) reported that chloride ions had more influence at corrosion resistance at $\mathrm{Cr}$ oxide formation than fluoride ions ${ }^{17}$.

The electrochemical parameters obtained from the polarization curves are shown in Table 3. The passive corrosion current $\left(\mathrm{I}_{\text {pass }}\right)$ values of Co-Cr-Mo alloy did not presented variations as the solution got more acid. This result shows that the corrosion resistance of the alloy is high at the potential of film formation. The analysis in mouthwash solution showed a lower passive current and a dislocation of corrosion potential to more anodic potential.

Chronoamperometry is a technique used for analyze the corrosion resistance. In this test methodology a fixed potential is applied during a period and the corrosion current variation generated at the material is measured. This method allows identifying if at the applied potential the corrosion resistance increases or decreases.

As it can be seen at polarization curves of Co-Cr-Mo alloy, $\mathrm{pH}$ of oxidant solution exerted significant influence in corrosion resistance of alloy at cathodic potentials. These results corroborate the chronoamperometry analysis (Figure
4). Figure 4(a) and 4(b) show the results obtained at potentials of $150 \mathrm{mV}$ and $-150 \mathrm{mV}$. As can be seen in all solutions the corrosion current was close to zero. This can be explained by the fact of these potentials been in passive region and the dissolution process does not occur. Figure 4(c) and 4(d) show the results of the analysis at $-300 \mathrm{mV}$ and $-800 \mathrm{mV}$. In these figures is possible to observe that the corrosion current increases at both potentials. The highest corrosion current was in the most acid solution in cathodic potentials. The highest corrosion current was at $\mathrm{pH} 2$. These results corroborated those obtained at potentiodynamic polarization curve. At more negative potential and more acid solution, the reduction process of hydrogen is significant, leading to increase of cathodic current.

Figure 5 shows the Nyquist diagram obtained by electrochemical impedance tests for $\mathrm{Cr}-\mathrm{Co}-\mathrm{Mb}$ alloy in different oxidizing environments. It can be seen that all the diagrams show a capacitive arc, which can be attributed to the capacitance of the double layer and the charge transfer resistance. The lower impedance values are associated with the interaction of Cr-Co$\mathrm{Mb}$ alloy with $0.9 \% \mathrm{NaCl}$ solution at $\mathrm{pH}$, the immersion of the alloy in mouthwash presented higher impedance values. From the Nyquist plots it was possible to calculate the polarization resistance, Rp and capacitance of the double layer to the alloy under the different conditions. The capacitance of the double layer was calculated according to the following equation,

$$
C_{d l}=\frac{1}{2 \pi f_{\max } R_{p}}
$$

The data obtained from electrochemical impedance tests are described in Table 4. It can be seen that the polarization resistance ( $\mathrm{Rp}$ ) of the alloy exposed to mouthwash was higher than the one exposed to $\mathrm{NaCl}$ solution, $\mathrm{pH} 2$ and $\mathrm{pH} 6$. The increase of $\mathrm{Rp}$ followed the reduction of the double layer capacitance. This behavior indicates that the oxide film formed is more resistant in this environment when compared to that formed in $0.9 \% \mathrm{NaCl}$ solution, $\mathrm{pH} 2$ and $\mathrm{pH} 6$. This result corroborates what was observed in the polarization curves and chronoamperometry. The polarization resistance is a way of knowing the corrosion resistance of a material in a corrosive environment. A higher polarization resistance is an indicative of a better corrosion resistance ${ }^{18-20}$.

Figure 6 shows the Bode diagram (phase angle versus $\log \mathrm{f}$ ), a typical behavior of passive film formation is observed at medium and low frequency. A similar behavior was verified by Souza et al. (2017) ${ }^{19}$ in their study about corrosion resistance of duplex steels. The frequency peak at approximately $10 \mathrm{~Hz}$ is characterized by a maximum phase angle, which decreases when the alloy is exposed to $0.9 \%$ $\mathrm{NaCl}$ solution. The increase in phase angle when the alloy is exposed to the mouthwash is indicative of the higher corrosion resistance of $\mathrm{CrCo}$ alloy in this environment. 


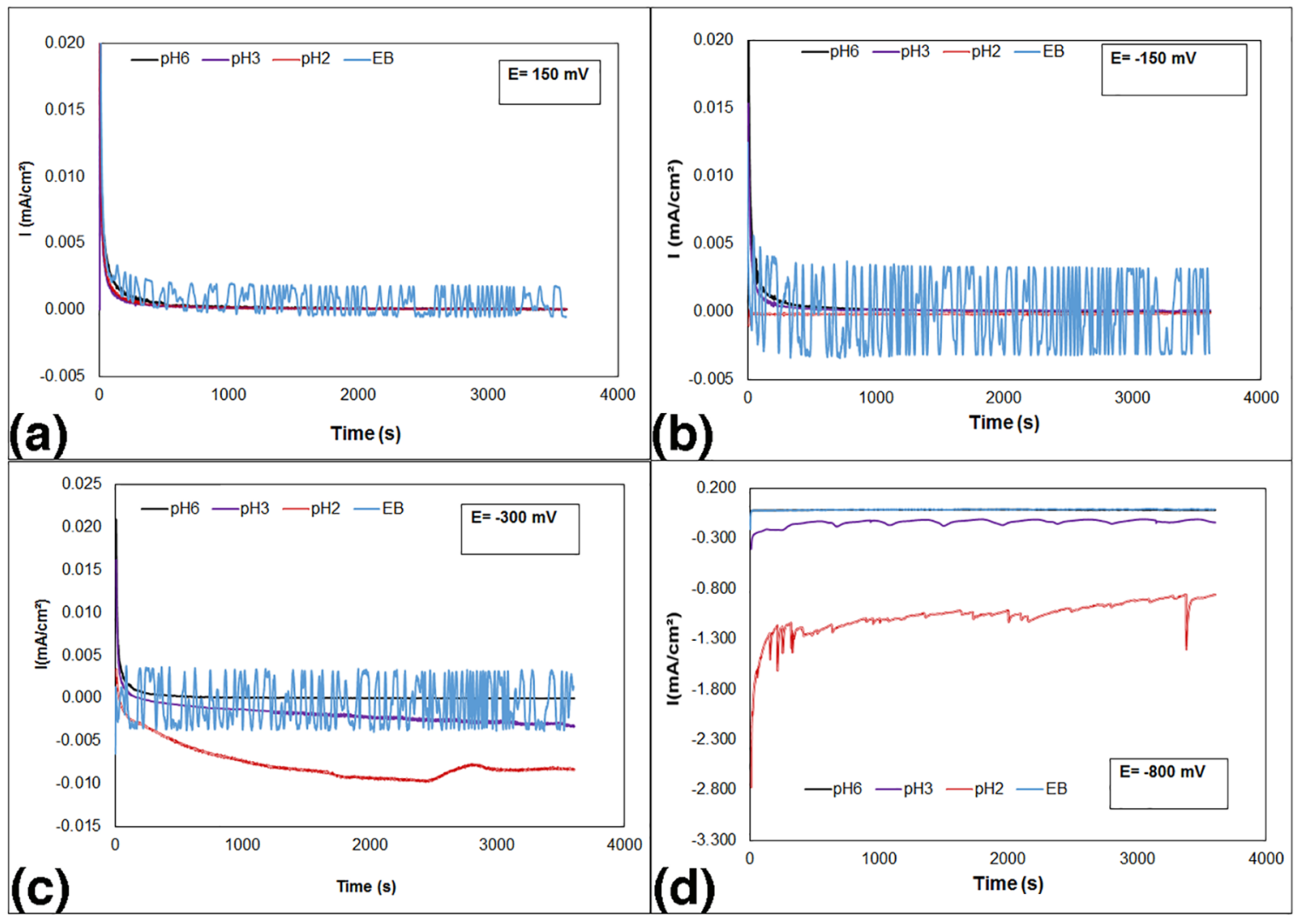

Figure 4. Chronoamperometry curves of Co-Cr-Mo alloy at different potential: (a) $150 \mathrm{mV}$; (b) $-150 \mathrm{mV}$; (c) $-300 \mathrm{mV}$; (d) $-800 \mathrm{mV}$

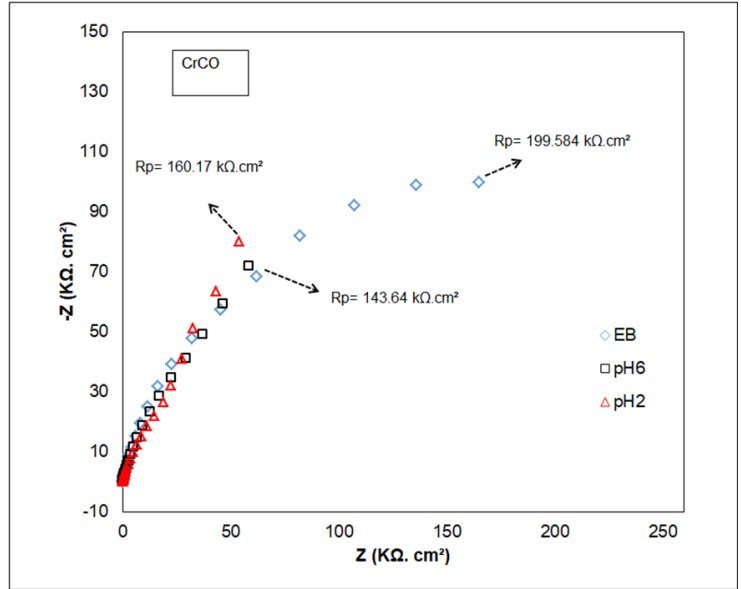

Figure 5. Nyquist Diagram of CoCrMo alloy in different solutions.

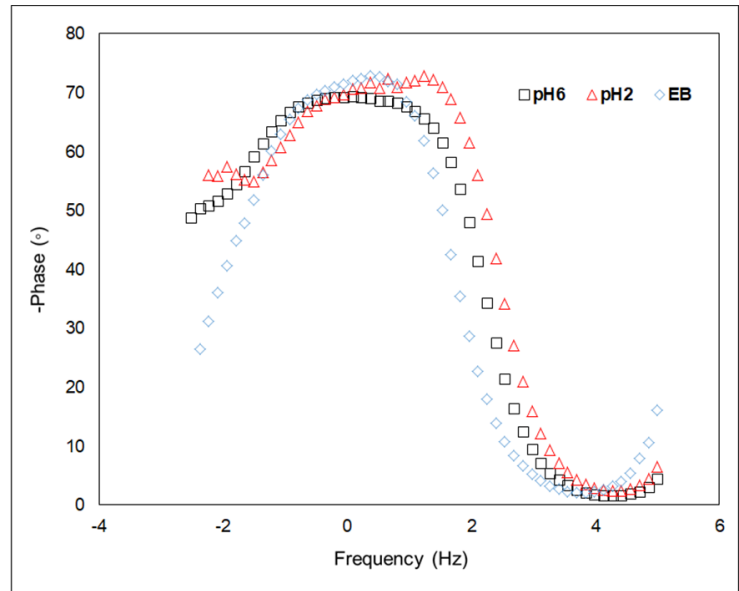

Figure 6. Bode Diagram of Co-Cr-Mo alloy in different solutions

Table 4. Electrochemical parameters obtained from the electrochemical impedance diagrams for CrCo alloy exposed to various corrosive environments.

\begin{tabular}{lccc}
\hline Corrosion Environment & $\mathbf{R p}\left(\mathbf{k} \boldsymbol{\Omega} \mathbf{~ c m}^{\mathbf{2}}\right)$ & $\mathbf{f m a x} \mathbf{( m H z})$ & $\mathbf{C d l}\left(\mathbf{m F} \mathbf{c m}^{-2}\right)$ \\
\hline $\mathrm{NaCl} 0.9 \% \mathrm{pH} 6$ & 143.64 & 5.8 & 18.99 \\
$\mathrm{NaCl} 0.9 \% \mathrm{pH} 2$ & 160.17 & 5.8 & 17.03 \\
$\mathrm{~EB} *$ & 199.58 & 5.8 & 13.67 \\
\hline
\end{tabular}

*EB - Mouthwash solution 


\section{Conclusions}

The corrosion behavior of Co-Cr-Mo alloy for dental implant prosthetic components application in saline and mouthwash solutions was investigated in terms of chronoamperometry (potentiostatic polarization) analysis, electrochemical impedance and, potentiodynamic polarization. The electrochemical tests used in this investigation led toward to the following conclusions.

a) The acidification of the $\mathrm{NaCl}$ solution influenced the Co-Cr-Mo alloy corrosion resistance.

b) The corrosion test in $\mathrm{pH} 2$ presented the highest cathodic and anodic corrosion current.

c) The corrosion test in mouthwash shows that $I_{\text {cor }}$ and $\mathrm{E}_{\text {corr }}$ are lower than in saline solution.

d) The electrochemical impedance results indicated that the sodium chloride solution is more aggressive than mouthwash solution mainly in acidic $\mathrm{pH}$.

\section{Acknowledgements}

This research was financially supported by Brazilian Agencies CNPq, FAPERJ and CAPES.

\section{References}

1. Revathi A, Borrás AD, MuñozAI, Richard C, Manivasagam G. Degradation mechanisms and future challenges of titanium and its alloys for dental implant applications in oral environment. Materials Science and Engineering: C. 2017;76:1354-68.

2. Anusavice KJ, Shen C, Rawls HR. Phillips - Materiais dentários. 12 ${ }^{\mathrm{a}}$ ed. Rio de Janeiro: Elsevier; 2013.

3. Ferreira DF, Lins VFC, Juliani L, Bracarense AQ, Junqueira R. Estudo da corrosão e tribocorrrosão do titânio ASTM-F67GR1 em solução de ringer. $70^{\circ}$ Congresso Anual da ABM Week; 2015 ago 17-21; Rio de Janeiro, Brasil. Rio de Janeiro (RJ): ABM; 2015. p. 884-93.

4. Harada R, Kokubu E, Kinoshita H, Yoshinari M, Ishihara K, Kawada E, et al. Corrosion behavior of titanium in response to sulfides produced by Porphyromonas gingivalis. Dental Materials. 2018;34(2):183-91.

5. Wang G, Wan Y, Wang T, Liu Z. Corrosion behavior of titanium implant with different surface morphologies. Procedia Manufacturing. 2017;10:363-70.

6. Kahraman N, Gulenc B, Findik F. Corrosion and mechanicalmicrostructural aspects of dissimilar joints of Ti-6Al-4V and Al plates. International Journal of Impact Engineering. $2007 ; 34^{(8)}: 1423-32$.

7. Agarwal A, Tyagi A, Ahuja A, Kumar N, De N, Bhutani H. Corrosion aspect of dental implants - an overview and literature review. Open Journal of Stomatology. 2014;4(2):56-60.

8. Gonçalves OD, Egito M, Castro C, Groisman S, Basílio M, Penha Junior NL. About the elemental analysis of dental implants. Radiation Physics and Chemistry. 2019;154:53-7.

9. Bakhtari A, Bradley TG, Lobb WK, Berzins DW. Galvanic corrosion between various combinations of orthodontic brackets and archwires. American Journal of Orthodontics and Dentofacial Orthopedics. 2011;140 ${ }^{(1)}: 25-31$.

10. Hanawa T. Metal ion release from metal implants. Materials Science and Engineering: C. 2004;12(6):745-52.

11. Schneider S, Rudolph M, Bause V, Terfort A. Electrochemical removal of biofilms from titanium dental implant surfaces. Bioelectrochemistry. 2018;121:84-94.

12. Hodgson AWE, Kurz S, Virtanen S, Fervel V, Olsson COA, Mischler S. Passive and transpassive behaviour of CoCrMo in simulated biological solutions. Electrochimica Acta. $2004 ; 49^{(13)}: 2167-78$.

13. Zhaman HA, Sharif S, Kim D, Idris M, Suhaimi M, Tumurkhuyag Z. Machinability of cobalt-based and cobalt chromium molybdenum alloys - a review. Procedia Engineering. 2017;11:563-70.

14. Sobral MAP, Luz MAAC, Gama-Teixeira A, Garone Netto N. Influência da dieta líquida ácida no desenvolvimento de erosão dental. Pesquisa Odontológica Brasileira. 2000;14(4):406-10.

15. Lopes AC, Rezende CEE, Fernandes MS, Weinfeld I. Infiltração bacteriana na interface implante/pilar: considerações ao implantodontista. Revista Gaúcha de Odontologia. 2010;58 (2):23942 .

16. Pourbaix M. Electrochemical corrosion of metallic biomaterials. Biomaterials. 1984;5 $5^{(3)}: 122-34$.

17. Silva JWJ, Sousa LL, Nakazato RZ, Codaro EN, Felipe H. Electrochemical and microstructural study of Ni-Cr-Mo alloys used in dental prostheses. Material Science and Applications. $2011 ; 2^{(1)}: 42-8$

18. Souza ECCA, Ripper BA, Perrone D, D’Elia E. Roasted coffee extracts as corrosion inhibitors for mild steel in $\mathrm{HCl}$ solution. Materials Research. 2016;19(6):1276-85.

19. Souza EC, Rossitti SM, Fortulan CA, Rollo JMDA. Influence of ferrite phase content on the electrochemical properties of duplex stainless steels. Materials Research. 2017;20(1):21-9.

20. Lima TM. Resistência à corrosão e biocompatibilidade de ligas Ti-35Nb-xTa submetidas à tratamentos de superfície [dissertação]. São Cristóvão (SE): Universidade Federal de Sergipe - Ciência e Engenharia de Materiais; 2018. 